Research

\title{
Wound infection in colorectal cancer resections through a laparoscopic approach: a single-center prospective observational study of over 3000 cases
}

\author{
Atsushi Ikeda ${ }^{1,2}$ - Yosuke Fukunaga ${ }^{1} \cdot$ Takashi Akiyoshi $^{1} \cdot$ Satoshi Nagayama ${ }^{1} \cdot$ Toshiya Nagasaki $^{1}$. \\ Tomohiro Yamaguchi $^{1} \cdot$ Toshiki Mukai $^{1} \cdot$ Yukiharu Hiyoshi ${ }^{1} \cdot$ Tsuyoshi Konishi $^{1,3}$
}

Received: 7 January 2021 / Accepted: 27 January 2021

(c) The Author(s) 2021 OPEN

\begin{abstract}
Objectives This prospective observational study aimed to clarify the incidence and independent risk factors of wound infection after laparoscopic surgery for primary colonic and rectal cancer.

Methods A prospective surveillance of surgical site infection (SSI) was conducted in consecutive patients with primary colorectal cancer, who underwent elective laparoscopic surgery in a single comprehensive cancer center between 2005 and 2014. The outcomes of interest were the incidence and risk factors of wound infection.

Results In total, 3170 patients were enrolled in the study. The overall incidence of wound infection was $3.0 \%$. The incidence of wound infection was significantly higher in rectal surgery than in colonic surgery (4.7 vs. $2.1 \%, p<0.001)$. In rectal surgery, independent risk factors for developing wound infection included abdominoperineal resection $(p<0.001$, odds ratio $[\mathrm{OR}]=11.4,95 \%$ confidence interval $[\mathrm{Cl}]: 5.04-24.8)$, body mass index $(\mathrm{BMI}) \geq 25 \mathrm{~kg} / \mathrm{m}^{2}(p=0.041, \mathrm{OR}=1.97$, $95 \% \mathrm{Cl}, 1.03-3.76)$, and chemoradiotherapy $(p=0.032, \mathrm{OR}=2.18,95 \% \mathrm{Cl}, 1.07-4.45)$. In laparoscopic colonic surgery, no significant risk factors were identified.

Conclusions Laparoscopic rectal surgery has a higher risk of wound infection than colonic surgery. Laparoscopic rectal surgery involving abdominoperineal resection, patients with higher BMI, and chemoradiotherapy requires careful observation in wound care and countermeasures against wound infection.
\end{abstract}

\section{Introduction}

Wound infection is one of the most frequent types of nosocomial infections, and it is a major cause of postoperative complications. Particularly in colorectal surgery, wound infection develops at a higher rate than in other types of operations [1], due to the high bacterial load present within the colorectal lumen. Although wound infection is rarely life-threatening, it occasionally leads to mortality. In addition, medical cost increases, hospital stay is prolonged, and the patient's quality of life decreases [2,3]. Therefore, prevention against wound infection has been regarded as one of the most important issues for colorectal surgeons $[4,5]$. In open procedures, rectal surgery has different incidence rates and risk factors of wound infection, compared with colon surgery $[6,7]$.

Since its introduction in 1991 [8], laparoscopic colorectal surgery has been performed at an increasing number of institutes, and many studies have demonstrated its advantage with regard to wound infection [9-12]. Such studies have

Tsuyoshi Konishi, tkonishi-tky@umin.ac.jp | ${ }^{1}$ Department of Gastroenterological Surgery, Cancer Institute Hospital of Japanese Foundation for Cancer Research, Tokyo, Japan. ²Department of Surgery, Graduate School of Medicine, Kyoto University, Kyoto, Japan. ${ }^{3}$ Department of Surgical Oncology, The University of Texas, M.D. Anderson Cancer Center, 1400 Pressler Street Unit 1484, Houston, TX 77030, USA. 
also evaluated the risk factors for wound infection after laparoscopic colorectal surgery [10, 13-16]. However, few studies with large sample sizes have focused on the differences in wound infection between laparoscopic colon and rectal cancer resections. Considering the higher technical demand in laparoscopic rectal cancer surgery compared with colonic, these two laparoscopic procedures might have different profiles that require different wound management approaches.

This study aimed to evaluate the differences in incidence rates and risk factors of wound infection between laparoscopic colon and rectal surgeries for primary colorectal cancer, using data from a prospective surveillance program of surgical site infection (SSI) at a single comprehensive cancer center.

\section{Methods}

\subsection{Surveillance methods and patient population}

From July 2005 to February 2014, all patients undergoing elective laparoscopic colorectal surgery for primary colorectal cancer were enrolled into a prospective SSI surveillance program at a single comprehensive cancer center in Japan. We prospectively collected the surveillance data, including the patients' demographics, surgical characteristics, and surgical outcomes with postoperative complications [14-21]. The primary outcome of interest was the incidence of wound infection, and the secondary outcome of interest was the independent risk factors of wound infection. Our SSI surveillance system was based on the U.S National Nosocomial Infections Surveillance (NNIS) system [22], and all the data were prospectively collected for at least 30 days after surgery.

$\mathrm{SSI}$, including wound infection, was defined according to the guidelines issued by the Center for Disease Control and Prevention [23]. Briefly, the criteria for incisional SSI were as follows: an infection occurring at the incision site within 30 days after the surgery, involving the skin, subcutaneous tissue, muscle, and fascia but not organ space, and at least one of the following: purulent drainage from the incision; an organism isolated from a culture of fluid from the incision; incisional pain, tenderness, localized swelling, redness, or heat; an incision that spontaneously dehisced or was deliberately opened by a surgeon considering the signs and symptoms of infection described previously. Superficial and deep incisional SSIs were evaluated together under the umbrella term "wound infection." Patients were assessed daily for SSI until discharge by attending physicians and nurses, with a follow-up of at least 30 days postoperatively in the outpatient clinic.

Colonic surgery was defined as procedures with anastomosis carried out above the peritoneal reflection, while rectal surgery was defined as those carried out below. Operative procedures were categorized as right colonic surgery, left colonic surgery, low anterior resection, intersphincteric resection, abdominoperineal resection (APR), and Hartmann's procedure. All procedures were performed or supervised by seven expert colorectal surgeons, each of whom had performed over 500 laparoscopic colorectal procedures and had a board-certification for endoscopic surgery from the Japan Society for Endoscopic Surgery.

\subsection{Preoperative protocols and surgical procedures}

All patients preoperatively underwent mechanical bowel preparation with oral laxative and magnesium citrate on the day before surgery, except in the cases of bowel obstruction by the tumor [24]. All patients also underwent chemical bowel preparation with $1 \mathrm{~g}$ of metronidazole and $750 \mathrm{mg}$ of kanamycin. For systemic antimicrobial prophylaxis, $1 \mathrm{~g}$ of cefmetazole was administered $30 \mathrm{~min}$ before the skin incision, repeated every $3 \mathrm{~h}$ during the operation, and stopped within $24 \mathrm{~h}$ after the surgery. Preoperatively, the patient's hair on the surgical field was shaved using electrical clippers on the day before surgery. After the induction of general anesthesia, the surgical site was wiped with povidone iodine solution and then covered with disposable drapes. Abdominal incisions were closed primarily with polydioxanone (PDS) monofilament absorbable sutures for both the fascia and skin. Subcutaneous drains were not used.

\subsection{Dependent and independent variables}

The outcome of interest was the incidence of wound infection. All of the independent variables were evaluated as categorical variables, including patient age in years $(\leq 60,61-70, \geq 71)$, sex, body mass index (BMI) in $\mathrm{kg} / \mathrm{m}^{2}(<25, \geq 25)$, American Society of Anesthesiologists (ASA) score $(1,2, \geq 3)$, presence of diabetes mellitus, tumor, node, metastasis (TNM) stage (I, II, III, IV, carcinoma in situ or adenoma, other types of tumor), operative procedure (right colonic surgery, 
left colonic surgery, low anterior resection, intersphincteric resection, APR, Hartmann's procedure), ostomy creation, duration of operation in hours $(<3,3-4, \geq 4)$, blood loss in $\mathrm{mL}(<100, \geq 100)$, and preoperative chemoradiotherapy. Other variables were categorical and are presented in the results.

\subsection{Statistical analysis}

Statistical analysis was performed using JMP software (version 14.0, SAS Institute Inc., Cary, NC, USA). The univariate relationships between each independent variable and wound infection were evaluated using Pearson's $\chi^{2}$ test or Fisher's exact test, as appropriate. Only variables with a $p$ value of less than 0.2 in the univariate analysis were included in a multivariate model of logistic regression, and the odds ratio, with $95 \%$ confidence intervals for each variable, were determined. $P$ values less than 0.05 were considered statistically significant.

\section{Results}

In total, 3170 patients underwent elective laparoscopic colorectal cancer surgery during the 106-month period, and all patients were admitted to our surveillance program, with all cases being eligible for the study. Of the total number of patients, 95 (3.0\%) were diagnosed with wound infection. Of all 3170 cases, 2037 (64\%) underwent colonic surgery and 1133 (36\%) underwent rectal surgery.

Table 1 shows the association between patient characteristics and wound infection after colonic and rectal surgeries. In univariate analysis, BMI and ASA score were statistically associated with the development of wound infection in rectal surgery ( $p=0.001$ and 0.016 , respectively). However, none of the variables were statistically associated with wound infection in colonic surgery.

Table 1 Patient characteristics and wound infection

\begin{tabular}{|c|c|c|c|c|c|c|}
\hline \multirow[t]{2}{*}{ Variables } & \multicolumn{3}{|c|}{ Colon $(n=2037)$} & \multicolumn{3}{|c|}{ Rectum $(n=1133)$} \\
\hline & $n$ & $\begin{array}{l}\text { Wound infec- } \\
\text { tion (\%) }\end{array}$ & $p$ & $n$ & $\begin{array}{l}\text { Wound infec- } \\
\text { tion (\%) }\end{array}$ & $p$ \\
\hline Age (year) & & & 0.471 & & & 0.547 \\
\hline$\leq 60$ & 671 & 1.9 & & 551 & 4.4 & \\
\hline $61-70$ & 700 & 2.6 & & 350 & 4.3 & \\
\hline$\geq 71$ & 666 & 1.7 & & 232 & 6.0 & \\
\hline Gender & & & 0.589 & & & 0.295 \\
\hline Female & 983 & 2.2 & & 463 & 3.9 & \\
\hline Male & 1054 & 1.9 & & 670 & 5.2 & \\
\hline BMI $\left(\mathrm{kg} / \mathrm{m}^{2}\right)$ & & & 0.939 & & & 0.001 \\
\hline$<25$ & 1562 & 2.1 & & 837 & 3.5 & \\
\hline$\geq 25$ & 475 & 2.1 & & 296 & 8.1 & \\
\hline ASA score & & & 0.596 & & & 0.016 \\
\hline 1 & 634 & 2.2 & & 446 & 2.9 & \\
\hline 2 & 1357 & 2.1 & & 664 & 5.6 & \\
\hline$\geq 3$ & 46 & 0 & & 22 & 13.6 & \\
\hline Diabetes mellitus & & & 0.729 & & & 0.205 \\
\hline+ & 115 & 0.9 & & 61 & 8.2 & \\
\hline- & 1922 & 2.1 & & 1072 & 4.5 & \\
\hline TNM stage & & & 0.752 & & & 0.901 \\
\hline I & 626 & 1.6 & & 416 & 4.1 & \\
\hline II & 513 & 2.3 & & 221 & 5.9 & \\
\hline III & 560 & 2.3 & & 338 & 5.0 & \\
\hline IV & 199 & 1.5 & & 60 & 3.3 & \\
\hline Carcinoma in situ or adenoma & 121 & 3.3 & & 42 & 4.8 & \\
\hline Other types of cancer & 18 & 0 & & 56 & 3.6 & \\
\hline
\end{tabular}

Italic signifies $p<0.05$ 
Table 2 shows the association between surgical characteristics and wound infection. In univariate analysis, surgical procedures, ostomy creation, duration of operation, blood loss, and chemoradiotherapy had significant correlations with the development of wound infection in rectal surgery $(p<0.001, p<0.001, p=0.004, p=0.002, p<0.001$, respectively). However, in colonic surgery, none of the variables associated statistically with the development of wound infection.

Table 3 summarizes the results of the multivariate logistic regression analysis. BMI, operative procedure (APR), and chemoradiotherapy were the independent risk factors for the development of wound infection after rectal surgery (BMI: $\mathrm{OR}=1.97,95 \% \mathrm{Cl}=1.03-3.76, p=0.041$, operative procedure [APR]: $\mathrm{OR}=11.2,95 \% \mathrm{Cl}=5.04-24.8, p<0.001$, and chemoradiotherapy: $\mathrm{OR}=2.18,95 \% \mathrm{Cl}=1.07-4.45, p=0.032$ ).

\section{Discussion}

This study found a higher incidence of wound infection in laparoscopic rectal resection than in colon resection and identified the risk factors for developing wound infection in a prospective dataset that included more than 3000 patients with colorectal cancer in a single cancer center. This is one of the largest series of SSI surveillance ever reported in the field of laparoscopic surgery for colorectal cancer $[25,26]$. In this prospective single-center study, the surgical procedures and perioperative managements were conducted under the unified protocol without variance among the providers, which possibly minimized the biases related to the different perioperative care among the providers, in contrast to the previous studies $[25,26]$.

In the present study, the incidence rates of wound infection were $2.1 \%(42 / 2037)$ in laparoscopic colonic surgery and $4.7 \%$ (53/1133) in laparoscopic rectal surgery, which is acceptable in comparison with the results of previous studies reported so far $[11,27,28]$. During the study period, the incidence of wound infection in elective open resections for primary colonic and rectal cancers were $4.3 \%$ (17/392) and $17.5 \%$ (28/160), respectively. Compared to these data, the present study clearly demonstrated that a laparoscopic approach was associated with lower rates of wound infection in

Table 2 Surgical characteristics and wound infection

\begin{tabular}{|c|c|c|c|c|c|c|}
\hline \multirow[t]{2}{*}{ Variable } & \multicolumn{3}{|c|}{ Colon $(n=2037)$} & \multicolumn{3}{|c|}{ Rectum $(n=1133)$} \\
\hline & No & $\begin{array}{l}\text { Wound infec- } \\
\text { tion (\%) }\end{array}$ & $p$ & No & $\begin{array}{l}\text { Wound infec- } \\
\text { tion (\%) }\end{array}$ & $p$ \\
\hline \multicolumn{7}{|l|}{ Procedures } \\
\hline Colon surgery & & & 0.566 & & & \\
\hline Right colectomy & 830 & 1.7 & & & & \\
\hline Left colectomy & 1201 & 2.3 & & & & \\
\hline Hartmann's procedure & 6 & 0 & & & & \\
\hline Rectal surgery & & & & & & $<0.001$ \\
\hline Low anterior resection & & & & 825 & 2.1 & \\
\hline Intersphicteric resection & & & & 165 & 0.6 & \\
\hline Abdominoperineal resection & & & & 133 & 25.6 & \\
\hline Hartmann's procedure & & & & 10 & 10.0 & \\
\hline Ostomy creation & & & 1.000 & & & $<0.001$ \\
\hline+ & 8 & 0 & & 598 & 7.2 & \\
\hline- & 2029 & 2.1 & & 535 & 1.9 & \\
\hline Duration of operation (hours) & & & 0.579 & & & 0.004 \\
\hline$<3$ & 733 & 1.6 & & 107 & 1.9 & \\
\hline $3-4$ & 797 & 2.4 & & 330 & 2.1 & \\
\hline$\geq 4$ & 507 & 2.2 & & 696 & 6.3 & \\
\hline Blood loss & & & 0.512 & & & 0.002 \\
\hline$<100 \mathrm{ml}$ & 1917 & 2.1 & & 944 & 3.7 & \\
\hline$\geq 100 \mathrm{ml}$ & 116 & 0.9 & & 189 & 9.5 & \\
\hline Chemoradiotherapy & & & & & & $<0.001$ \\
\hline+ & 0 & 0 & & 269 & 10.8 & \\
\hline - & 2030 & 2.1 & & 864 & 2.8 & \\
\hline
\end{tabular}

Italic signifies $p<0.05$ 
Table 3 Multivariate logistic regression analysis for risk factors of wound infection in rectal surgery

\begin{tabular}{lclr}
\hline Variable & Odds ratio & $95 \% \mathrm{Cl}$ & $p$ \\
\hline $\mathrm{BMI} \geq 25$ & 1.97 & $1.03-3.76$ & 0.041 \\
$\mathrm{ASA}$ & & & \\
1 & & Reference value & 0.096 \\
2 & 1.85 & $0.90-3.80$ & 0.063 \\
$\geq 3$ & 4.90 & $0.92-26.2$ & \\
Operation & & & 0.146 \\
Low anterior resection & & Reference value & $<0.001$ \\
$\quad$ Intersphicteric resection & 0.21 & $0.03-1.71$ & 0.268 \\
$\quad$ Abdominoperineal resection & 11.2 & $5.04-24.8$ & 0.146 \\
$\quad$ Hartmann's procedure & 3.57 & $0.37-34.1$ & \\
Ostomy creation & 1.12 & $0.43-2.90$ & \\
Duration of operation & & & 0.780 \\
$<3$ & & Reference value & 0.642 \\
$3-4$ & 0.79 & $0.15-4.10$ & 0.507 \\
$\geq 4$ & 1.44 & $0.31-6.60$ & 0.032 \\
Blood loss & & $0.38-1.61$ & $1.07-4.45$ \\
$\geq 100$ ml & 0.78 & & \\
Chemoradiaotherapy & 2.18 & & \\
\hline
\end{tabular}

Italic signifies $p<0.05$

ASA American Society of Anesthesiologists, BMI body mass index, Other types of tumors include carcinoids and gastrointestinal stromal tumors

colon and rectal procedures ( $p=0.012$ and $<0.001$, respectively). Consistent with the results of previous studies [27], our findings confirmed the advantage of laparoscopic surgery in reducing wound infection in both colonic and rectal cancer surgeries. In laparoscopic colonic surgery, the outcome events are so rare that no risk factor can be found in a study even with such a large number of cases. In other words, with sophisticated surgical techniques and well-trained perioperative management, wound infection after laparoscopic colonic surgery can be reduced to minimal incidence. In contrast, after laparoscopic rectal surgery, BMI $>25 \mathrm{~kg} / \mathrm{m}^{2}$, operative procedure (APR), and chemoradiotherapy were found to be independent risk factors for the development of wound infection, which suggests the need for careful observation in wound care and countermeasures against wound infection in these patients.

Many studies have investigated the relationship between obesity and wound infection in laparoscopic colorectal surgery [29-31]. Some studies have demonstrated a significant association between obesity and wound infection, which might be explained by increased fractions of visceral fat, higher incidence of metabolic syndrome, and a narrow pelvis [30]. In the present study, the incidence of wound infection after laparoscopic colonic surgery was similar between patients with higher and lower BMI. In rectal surgery, however, wound infection developed with a significantly higher rate in patients with higher BMI. Laparoscopic rectal surgery in obese patients is particularly challenging because of the difficulty in accessing the pelvic operative field, and high BMI is reportedly associated with a higher incidence of postoperative complications [32-34]. Attention is required in perioperative wound care after laparoscopic rectal surgery in patients with higher BMI.

APR is reportedly associated with a high incidence of perineal wound complications, up to 58\% [35]. After the rectum is excised, the sacral cavity forms a large wound area, which leads to fluid collection and results in pelvic abscess. Similarly, in the present study, laparoscopic APR was associated with a higher incidence of wound infection, compared with other procedures. Interestingly, patients who underwent open APR during the same period in our institute developed wound infection with a rate of $31.5 \%$ (17/54), which is similar to the rate in laparoscopic APR $(25.6 \%)$ in this study. The perineal procedure in APR is the same, regardless of open or laparoscopic approaches, which likely eliminates the benefit of the laparoscopic approach in terms of reducing wound infection. APR often requires longer operative time than other colorectal resections due to the time-consuming perineal procedure [36], which further increases the risk of wound infection. The incidence of wound infection in the perineal wound was further elevated by chemoradiotherapy [37], and 33.3\% (25/75) of the patients who underwent laparoscopic APR after chemoradiotherapy developed wound 
infection in this study. In light of these findings, management of the perineal wound in APR is a matter of concern in laparoscopic surgery and requires further improvement.

The strengths of this study include prospective surveillance data with a large sample size, unified perioperative management under a predefined protocol, and a study cohort that focused on laparoscopic surgery for colorectal cancer at a comprehensive cancer center. However, the study has limitations inherent to a single center study. Although we identified higher BMI as a risk factor for wound infection in rectal cancer, data from a specialty institution in Japan, where patients are generally fit and non-obese, have the potential for limited applicability. The generalizability of the present findings should be validated in different cohorts with higher BMI values. Despite these limitations, our findings clearly identified different profiles of wound infection between laparoscopic colon and rectal cancer resections. Further studies are required to reveal the need for different wound management approaches in these procedures.

In conclusion, laparoscopic rectal surgery has a higher risk of wound infection, compared with laparoscopic colonic surgery, with distinct profiles of the risk factors. Laparoscopic rectal surgery involving abdominoperineal resection, patients with higher BMI, and chemoradiotherapy requires careful observation in wound care and countermeasures against wound infection.

Authors' contributions Conception and design: TK. Development of methodology: Al, TK. Data acquisition: Al, YF, TA, SN, TN, TY, TM, YH, and TK. Analysis and interpretation of data: Al, TK. Draft writing, review, and/or revision of the manuscript: Al, TK. Final approval of the manuscript: Al, YF, TA, SN, TN, TY, TM, YH, and TK. All authors read and approved the final manuscript.

Funding No funding was received to assist with the preparation of this manuscript.

Data availability The datasets generated and analyzed in this study are available from the corresponding author upon reasonable request.

Competing interests The authors declare no competing interests.

Open Access This article is licensed under a Creative Commons Attribution 4.0 International License, which permits use, sharing, adaptation, distribution and reproduction in any medium or format, as long as you give appropriate credit to the original author(s) and the source, provide a link to the Creative Commons licence, and indicate if changes were made. The images or other third party material in this article are included in the article's Creative Commons licence, unless indicated otherwise in a credit line to the material. If material is not included in the article's Creative Commons licence and your intended use is not permitted by statutory regulation or exceeds the permitted use, you will need to obtain permission directly from the copyright holder. To view a copy of this licence, visit http://creativecommons.org/licenses/by/4.0/.

\section{References}

1. National Nosocomial Infections Surveillance S. National Nosocomial Infections Surveillance (NNIS) System Report, data summary from January 1992 through June 2004, issued October 2004. Am J Infect Control. 2004;32(8):470-85. https://doi.org/10.1016/S019665530 4005425.

2. Kirkland KB, Briggs JP, Trivette SL, Wilkinson WE, Sexton DJ. The impact of surgical-site infections in the 1990s: attributable mortality, excess length of hospitalization, and extra costs. Infect Control Hosp Epidemiol. 1999;20(11):725-30. https://doi.org/10.1086/501572.

3. Mahmoud NN, Turpin RS, Yang G, Saunders WB. Impact of surgical site infections on length of stay and costs in selected colorectal procedures. Surg Infect (Larchmt). 2009;10(6):539-44. https://doi.org/10.1089/sur.2009.006.

4. Smith RL, Bohl JK, McElearney ST, Friel CM, Barclay MM, Sawyer RG, et al. Wound infection after elective colorectal resection. Annals Surg. 2004;239(5):599-607. https://doi.org/10.1097/01.sla.0000124292.21605.99.

5. Weiss CA, Statz CL, Dahms RA, Remucal MJ, Dunn DL, Beilman GJ. Six years of surgical wound infection surveillance at a tertiary care center: review of the microbiologic and epidemiological aspects of 20,007 wounds. Arch Surg. 1999;134(10):1041-8.

6. Konishi T, Watanabe T, Kishimoto J, Nagawa H. Elective colon and rectal surgery differ in risk factors for wound infection: results of prospective surveillance. Ann Surg. 2006;244(5):758-63. https://doi.org/10.1097/01.sla.0000219017.78611.49.

7. Konishi T, Watanabe T, Kishimoto J, Nagawa H. Risk factors for anastomotic leakage after surgery for colorectal cancer: results of prospective surveillance. J Am Coll Surg. 2006;202(3):439-44. https://doi.org/10.1016/j.jamcollsurg.2005.10.019.

8. Jacobs M, Verdeja JC, Goldstein HS. Minimally invasive colon resection (laparoscopic colectomy). Surg Laparosc Endosc. 1991;1(3):144-50.

9. Kulkarni N, Arulampalam T. Laparoscopic surgery reduces the incidence of surgical site infections compared to the open approach for colorectal procedures: a meta-analysis. Tech Coloproctol. 2020;24(10):1017-24. https://doi.org/10.1007/s10151-020-02293-8.

10. Yamamoto S, Ito M, Okuda J, Fujii S, Yamaguchi S, Yoshimura K, et al. Laparoscopic surgery for stage 0/I rectal carcinoma: short-term outcomes of a single-arm phase II trial. Ann Surg. 2013;258(2):283-8. https://doi.org/10.1097/SLA.0b013e318283669c.

11. Poon JT, Law WL, Wong IW, Ching PT, Wong LM, Fan JK, et al. Impact of laparoscopic colorectal resection on surgical site infection. Ann Surg. 2009;249(1):77-81. https://doi.org/10.1097/SLA.0b013e31819279e3.

12. Romy S, Eisenring MC, Bettschart V, Petignat C, Francioli P, Troillet N. Laparoscope use and surgical site infections in digestive surgery. Ann Surg. 2008;247(4):627-32. https://doi.org/10.1097/SLA.0b013e3181638609. 
13. Sciuto A, Merola G, De Palma GD, Sodo M, Pirozzi F, Bracale UM, et al. Predictive factors for anastomotic leakage after laparoscopic colorectal surgery. World J Gastroenterol. 2018;24(21):2247-60. https://doi.org/10.3748/wjg.v24.i21.2247.

14. Mukai T, Akiyoshi T, Ueno M, Fukunaga Y, Nagayama S, Fujimoto Y, et al. Outcomes of laparoscopic surgery for colorectal cancer in oldestold patients. Surg Laparosc Endosc Percutan Tech. 2014;24(4):366-9. https://doi.org/10.1097/SLE.0b013e31829012ca.

15. Akiyoshi T, Kuroyanagi H, Oya M, Ueno M, Fujimoto $Y$, Konishi T, et al. Factors affecting difficulty of laparoscopic surgery for left-sided colon cancer. Surg Endosc. 2010;24(11):2749-54. https://doi.org/10.1007/s00464-010-1039-5.

16. Akiyoshi T, Kuroyanagi H, Fujimoto $Y$, Konishi T, Ueno M, Oya M, et al. Short-term outcomes of laparoscopic colectomy for transverse colon cancer. J Gastrointest Surg. 2010;14:818-23.

17. Ikeda A, Fukunaga Y, Akiyoshi T, Konishi T, Fujimoto Y, Nagayama S, et al. Laparoscopic right colectomy in patients treated with previous gastrectomy. Surg Today. 2016;46(2):209-13. https://doi.org/10.1007/s00595-015-1157-8.

18. Akiyoshi T. Technical feasibility of laparoscopic extended surgery beyond total mesorectal excision for primary or recurrent rectal cancer. World J Gastroenterol. 2016;22(2):718-26. https://doi.org/10.3748/wjg.v22.i2.718.

19. Nagasaki T, Akiyoshi T, Ueno M, Fukunaga Y, Nagayama S, Fujimoto Y, et al. Feasibility and safety of laparoscopic surgery for metachronous colorectal cancer. Surg Today. 2014. https://doi.org/10.1007/s00595-014-0925-1.

20. Nagasue Y, Akiyoshi T, Ueno M, Fukunaga Y, Nagayama S, Fujimoto Y, et al. Laparoscopic versus open multivisceral resection for primary colorectal cancer: comparison of perioperative outcomes. J Gastrointest Surg. 2013;17(7):1299-305. https://doi.org/10.1007/s1160 5-013-2222-5.

21. Ueno M, Oya M, Azekura K, Yamaguchi T, Muto T. Incidence and prognostic significance of lateral lymph node metastasis in patients with advanced low rectal cancer. Br J Surg. 2005;92(6):756-63. https://doi.org/10.1002/bjs.4975.

22. Emori TG, Culver DH, Horan TC, Jarvis WR, White JW, Olson DR, et al. National nosocomial infections surveillance system (NNIS): description of surveillance methods. Am J Infect Control. 1991;19(1):19-35. https://doi.org/10.1016/0196-6553(91)90157-8.

23. Mangram AJ, Horan TC, Pearson ML, Silver LC, Jarvis WR. Guideline for prevention of surgical site infection, 1999. Hospital Infection Control Practices Advisory Committee. Infect Control Hosp Epidemiol. 1999;20(4):250-78. https://doi.org/10.1086/501620.

24. Ikeda A, Konishi T, Ueno M, Fukunaga Y, Nagayama S, Fujimoto Y, et al. Randomized clinical trial of oral and intravenous versus intravenous antibiotic prophylaxis for laparoscopic colorectal resection. Br J Surg. 2016;103(12):1608-15. https://doi.org/10.1002/bjs.10281.

25. Kurmann A, Vorburger SA, Candinas D, Beldi G. Operation time and body mass index are significant risk factors for surgical site infection in laparoscopic sigmoid resection: a multicenter study. Surg Endosc. 2011;25(11):3531-4. https://doi.org/10.1007/s00464-011-1753-7.

26. Kitano S, Kitajima M, Konishi F, Kondo H, Satomi S, Shimizu N. A multicenter study on laparoscopic surgery for colorectal cancer in Japan. Surg Endosc. 2006;20(9):1348-52. https://doi.org/10.1007/s00464-004-8247-9.

27. Yamamoto S, Inomata M, Katayama H, Mizusawa J, Etoh T, Konishi F, et al. Short-term surgical outcomes from a randomized controlled trial to evaluate laparoscopic and open D3 dissection for stage II/III colon cancer. Ann Surg. 2014;260(1):23-30. https://doi.org/10.1097/ SLA.0000000000000499.

28. Yamamoto S, Fujita S, Akasu T, Ishiguro S, Kobayashi Y, Moriya Y. Wound infection after elective laparoscopic surgery for colorectal carcinoma. Surg Endosc. 2007;21(12):2248-52. https://doi.org/10.1007/s00464-007-9358-x.

29. Makino T, Trencheva K, Shukla PJ, Rubino F, Zhuo C, Pavoor RS, et al. The influence of obesity on short- and long-term outcomes after laparoscopic surgery for colon cancer: a case-matched study of 152 patients. Surgery. 2014. https://doi.org/10.1016/j.surg.2014.03.023.

30. Gurunathan U, Ramsay S, Mitric G, Way M, Wockner L, Myles P. Association between obesity and wound infection following colorectal surgery: systematic review and meta-analysis. J Gastrointest Surg. 2017;21(10):1700-12. https://doi.org/10.1007/s11605-017-3494-y.

31. Gendall KA, Raniga S, Kennedy R, Frizelle FA. The impact of obesity on outcome after major colorectal surgery. Dis Colon Rectum. 2007;50(12):2223-37. https://doi.org/10.1007/s10350-007-9051-0.

32. Akiyoshi T, Ueno M, Fukunaga Y, Nagayama S, Fujimoto Y, Konishi T, et al. Effect of body mass index on short-term outcomes of patients undergoing laparoscopic resection for colorectal cancer: a single institution experience in Japan. Surg Laparosc Endosc Percutan Tech. 2011;21(6):409-14. https://doi.org/10.1097/SLE.0b013e31822e5fdc.

33. Gurunathan U, Ramsay S, Mitrić G, Way M, Wockner L, Myles P. Association between obesity and wound infection following colorectal surgery: systematic review and meta-analysis. J Gastrointest Surg. 2017;21(10):1700-12. https://doi.org/10.1007/s11605-017-3494-y.

34. Pikarsky AJ, Saida Y, Yamaguchi T, Martinez S, Chen W, Weiss EG, et al. Is obesity a high-risk factor for laparoscopic colorectal surgery? Surg Endosc. 2002;16(5):855-8. https://doi.org/10.1007/s004640080069.

35. de Bruin AF, Gosselink MP, Wijfels NA, Coene PP, van der Harst E. Local gentamicin reduces perineal wound infection after radiotherapy and abdominoperineal resection. Tech Coloproctol. 2008;12(4):303-7. https://doi.org/10.1007/s10151-008-0440-8.

36. Perry WB, Connaughton JC. Abdominoperineal resection: how is it done and what are the results? Clin Colon Rectal Surg. 2007;20(3):21320. https://doi.org/10.1055/s-2007-984865.

37. Musters GD, Buskens CJ, Bemelman WA, Tanis PJ. Perineal wound healing after abdominoperineal resection for rectal cancer: a systematic review and meta-analysis. Dis Colon Rectum. 2014;57(9):1129-39. https://doi.org/10.1097/DCR.0000000000000182.

Publisher's Note Springer Nature remains neutral with regard to jurisdictional claims in published maps and institutional affiliations. 